\title{
Ciudadanía Cultural en estudiantes de Escuelas Normales públicas de Ciudad de México
}

\author{
Cultural Citizenship in students of Public \\ Normal Schools of Mexico city \\ Hilda Aguayo Rousell \\ Secretaría de Educación Pública \\ Universidad Nacional Autónoma de México \\ hildaberenice20@hotmail.com
}

\begin{abstract}
Resumen
El objetivo de la investigación fue explorar las actitudes y manifestaciones de aceptación, rechazo y/o discriminación frente a las poblaciones indígenas en estudiantes de 5 escuelas normales públicas de la Ciudad de México, como rasgos de su ciudadanía cultural. Participaron 319 alumnos. Se utilizó la asociación de palabras con el término inductor indígenas y se emplearon redes semánticas con 3 categorías: aceptación, discriminación y denuncia. En los resultados se encontró que en la red total de palabras sí hubo expresiones de discriminación, pero en el núcleo de la red únicamente hubo términos de aceptación y denuncia. Se concluye que aun cuando se señala reiteradamente que no hay discriminación hacia estas comunidades, las expresiones cotidianas muestran lo contrario. Aunque existen asignaturas curriculares específicas sobre Educación Ciudadana, pocas instituciones normalistas enfatizan la formación de los docentes como ciudadanos, soslayando la importancia de esta dimensión en un país como México, que intenta avanzar hacia la democracia.
\end{abstract}

Palabras clave: ciudadanía cultural, discriminación, estudiantes, indígenas.

\begin{abstract}
The objective of the research was to explore the attitudes and manifestations of acceptance, rejection and / or discrimination against indigenous populations in students of 5 public normal schools in Mexico City, as features of their cultural citizenship. 319 students participated. Association of words with the term indigenous inductor was used and semantic networks with 3 categories were used: acceptance, discrimination and denunciation. In the results it was found that in the total word network there were expressions of discrimination, but in the core of the network there were only terms of acceptance and denunciation. It is concluded that even when it is repeatedly pointed out that there is no discrimination towards these communities, everyday expressions show the opposite. Although there are specific curricular subjects on Civic
\end{abstract}

Hilda Aguayo Rousell

Ciudadanía Cultural en estudiantes de Escuelas Normales públicas de Ciudad de México. Autoctonía. Revista de Ciencias Sociales e Historia, Vol. III, N², Julio-Diciembre 2019, 159-184 ISSN 0719-8213

DOI: http://doi.org/10.23854/autoc.v3i2.118 
Education, few normal schools institutions emphasize the training of teachers as citizens, overlooking the importance of this dimension in a country like Mexico, which is trying to move towards democracy.

Keywords: cultural citizenship, discrimination, students, indigenous.

Recibido: 29 de Mayo de 2019 - Aceptado: 07 de Agosto de 2019

\section{Introducción}

La noción de ciudadanía remite a la relación entre el individuo y el Estado, basada en un conjunto de normas y prescripciones relacionadas con los derechos y obligaciones de los ciudadanos y las responsabilidades del Estado con respecto a éstos (Durand, 2004). El primero que señala la existencia de diversos tipos de ciudadanía es Marshall (1967), quien la divide en civil -derechos y obligaciones relacionados con la libertad individual-; política -vinculada con la participación y el poder político-y social-relativa a un estado de seguridad y bienestar mínimo-. Sin embargo, los avances tecnológicos de las últimas décadas y la era de la globalización han generado nuevas necesidades de convivencia; fenómenos como la migración, el desplazamiento laboral, la comercialización trasnacional de bienes mercantiles y culturales, entre otros, hacen imposible acotarla a las 3 esferas señaladas por Marshall (1967). Para García-Canclini (1995), la ciudadanía es sinónimo de ciudadanos y no puede reducirse a los derechos civiles o políticos, por tanto, utiliza el término ciudadanía cultural para referirse a las diferentes manifestaciones culturales asociadas con la diversidad humana.
Según Ramírez (2005), es el propio contexto internacional el que da lugar al surgimiento de la denominada ciudadanía global, en donde distingue 4 dimensiones: civil, socioeconómica, política y cultural.

La Ciudadanía Cultural hace referencia al conjunto de actitudes y comportamientos que la persona asume como resultado de habitar un territorio común, en convivencia con diversos grupos sociales que poseen rasgos y tradiciones culturales distintas (Touraine, 2005, 1997; Ramírez, 2005). Sus interacciones cotidianas se realizan en un clima de respeto, tolerancia e igualdad entre todos, sin importar edad, sexo, condición social, física o económica; tampoco origen, ni preferencias políticas, sexuales o religiosas. En sociedades más conservadoras, se presenta en menor grado y como consecuencia aflora el fenómeno de la denominada intolerancia cultural (Wieviorka, 2007; Cisneros, 2004), que se manifiesta en actitudes racistas, de menosprecio, rechazo, burlas, estigmas, discriminación hacia aquellos grupos o individuos que no comparten las tradiciones culturales de la mayoría. "El concepto de racismo nos lleva al discutido tema de las identidades y nos remite 
a la xenofobia, las discriminaciones y exclusiones, es un tema que durante muchos años fue soslayado en nuestro país" (Stavenhagen, 2014: 229). El autor recupera la idea de la persistente presencia del racismo en la sociedad mexicana como fenómeno vigente, sutil o no tan sutil, expresado en comportamientos subjetivos y prácticas institucionales sostenidas en las estructuras sociales más profundas y ancladas en una historia de relaciones profundamente desiguales durante la conquista y la independencia.

Moreno (2016) subraya la urgencia de reconocer la existencia del racismo como eje central en las interacciones cotidianas y en las estructuras institucionales en la sociedad mexicana, apuntando su magnitud al convertirse en parámetro para establecer relaciones de exclusión/inclusión, y estudiando el vínculo tan estrecho entre racismo y discriminación, señalando la importancia de su distinción:

me he encontrado con frecuencia con la tensión entre el uso conceptual de los términos racismo y discriminación [...entender] el término racismo como un sistema totalizante u estructural y distinguirlo de la discriminación como un acto específico de diferenciación relacionado con alguna forma de injusticia (Moreno, 2016: 101).

Estudiar la discriminación resulta imperante porque durante mucho tiempo se ha pensado que es un hecho individual y aislado, resultado de una problemática individual, lo cual ha sido cuestionado reiteradamente por los especialistas (Gutiérrez, 2005; Rodríguez, 2006). La Ley Federal para Prevenir y Eliminar la Discriminación (SEGOB, 2014) la define como:

un fenómeno que se sustenta en una visión dominante de que unas personas pueden ser superiores a otras por su origen social, por el color de su piel, por la lengua que hablan, por su apariencia física, su edad, su identidad de género o preferencia sexual, o por cualquier otro motivo (p. 5).

Giménez (2007) utiliza el término etnicismo para referirse a la ideología de inferiorización que discrimina a los grupos étnicos por sus diferencias culturales; establece que el fenómeno de la discriminación en el fondo esconde un problema de reconocimiento de identidad atribuida por "los otros" y enfatiza que las diferencias culturales posicionan, otorgan un lugar a cada uno de los grupos sociales, los del poder [dominantes] y los que se subsumen o rebelan [dominados]. Para este autor, las fuentes o motivos de la discriminación son 3 principales: el etnocentrismo exacerbado; la intolerancia cultural y el prejuicio inferiorizante en razón del origen étnico (etnicismo); de los rasgos físicos (racismo); de las diferencias de género (sexismo) y de la procedencia extranjera (xenofobia), aun cuando no existan diferencias culturales considerables. En México, diversos especialistas (Castellanos, 2012, 2010; Gall, 2016, 2014; Stavenhagen, 2014) han documentado la presencia de múltiples prácticas de discriminación hacia los 
indígenas en diversas dimensiones de la vida social, señalando reiteradamente las situaciones de sobrevivencia, desigualdad e injusticia que ha caracterizado a estos grupos por siglos.

\section{Referentes Conceptuales}

La Ciudadanía Cultural es propia de las sociedades abiertas y plurales; se acepta y respeta a las minorías reconociéndoles sus derechos individuales y sociales; se nutre de las diversas expresiones humanas, que a su vez son manifestaciones culturales (García-Canclini, 1995). A través de la cultura, el individuo encuentra su identidad y pertenencia social; desde estas semejanzas y diferencias con otros grupos es capaz de establecer un diálogo e intercambio de tradiciones, las cuales se enriquecen recíprocamente. Cuando en comunidades más amplias se insertan grupos minoritarios generalmente vulnerables, se presentan situaciones que son reflexionadas desde la perspectiva de la Ciudadanía Cultural: la primera enfatiza el derecho a conservar las diferencias culturales, siempre que sus prácticas no lesionen la dignidad ni los derechos humanos de sus integrantes (Kymlicka, 1996; Kymlicka y Norman, 1997; Taylor, 2009; Touraine, 2005; Aragón, 2015; Benhabib, 2006; Ferrajoli, 2008)1. La segunda señala su derecho a ser tratados en situación de igualdad y justicia con respecto a los grupos mayoritarios (Beuchot, 2005). Estos dos señalamientos recuperan la esencia de la Ciudadanía Cultural, enfatizando el derecho de estas comunidades a las identidades colectivas (Knauth, 2000). Cuando las minorías se in- corporan a una comunidad mayor, que puede ser otro país u otra región, el grupo dominante impone su cultura; las minorías deberán aceptar las normas y leyes del Estado sin renunciar a sus tradiciones culturales, siempre que éstas no lesionen los derechos humanos fundamentales.

Según Kymlicka, la diversidad cultural tiene su origen en la incorporación de diferentes culturas -que él denomina minorías nacionales-a diversas comunidades políticas. Su característica principal es su deseo de continuar como "sociedades distintas respecto de la cultura mayoritaria de la que forman parte; exigen, por tanto, diversas formas de autonomía o autogobierno para asegurar su supervivencia como sociedades distintas" (Kymlicka, 1996: 26). Este fenómeno tiene que ver primordialmente con el reconocimiento de los derechos culturales que benefician a poblaciones particulares, generalmente minoritarias. Los derechos sociales y políticos son para todos los ciudadanos por igual, pero los derechos culturales están centrados en la libertad del sujeto y protegen a minorías, como lo señala Touraine (2005):

los derechos culturales no se dirigen sólo a la protección de una herencia o a la diversidad de las prácticas sociales; obligan a reconocer [...] que cada uno, individual y colectivamente, puede construir condiciones de vida y transformar la vida social en función de su manera de combinar los principios generales de la modernización y las <identidades particulares (p. 184). 
En este artículo interesa documentar algunos trabajos de corte empírico que analizan manifestaciones explícitas o no de prácticas racistas, sean individuales o institucionales generadas en contextos que generalmente no reconocen la vigencia del racismo; se encontró que en España autores como Borasteros y García (2007), así como Cea (2009), documentan diversas prácticas de discriminación racial hacia migrantes e hijos de indígenas en el contexto escolar. Es de vital importancia señalar estos trabajos porque dan cuenta de que el fenómeno de la discriminación no es exclusivo de América Latina, ni tampoco de ciertos sectores de la población; su presencia explícita o velada continúa permeando las interacciones cotidianas en todas las esferas de la sociedad.

En América Latina, Ojeda y González (2012) en Colombia; Casaús (2009) en Guatemala; Pávez (2012) en Chile; Rahier (2013), Traverso-Yépez (2005) y Placencia (2008) en Ecuador, informan sobre estudios que constatan la presencia de manifestaciones asociadas con el racismo, la xenofobia y discriminación hacia poblaciones autóctonas. En México, Saldaña (2013) también reporta expresiones de racismo hacia las mujeres del servicio doméstico; Hernández y Estrada (2012) en niños indígenas en La Merced, mientras Hamel (2001) lo documenta en escuelas indígenas bilingües.

Autores como Castellanos (2012, 2010); Casaús (2009); Paris (2008) y Gall $(2016,2014)$ fundamentan cómo las maniobras de colonización por parte de los europeos hacia las regiones de Centro y Sudamérica, África y Asia durante los siglos XV, XVI y XVII, a la par del surgimiento de nuevos Estados nacionales y las nacientes teorías raciales del siglo XIX (Wade, 2014, 2011; Knauth, 2000) dan lugar a procesos de diferenciación racial que justifican relaciones de poder, emergiendo fenómenos como el estigma, la intolerancia y la exclusión hacia los grupos menos favorecidos.

Para el caso de México, su desarrollo histórico ha propiciado que a partir de la conquista y colonización, la sociedad mexicana esté conformada por diferentes grupos con características étnicas y culturales diversas como indígenas, mestizos, blancos y afromexicanos (Stavenhagen, 2014), lo cual ha dado como resultado el mosaico cultural de la población actual (Castellanos, 2012, 2010; Gall, 2016). Diversos proyectos emanados desde iniciativas gubernamentales han intentado la integración social, económica y cultural de los grupos indígenas, pero dichas gestiones no han tenido los resultados esperados, alcanzando en la actualidad altos niveles de marginación estructural y social que los mantiene en situaciones de pobreza y miseria en algunos casos extremas (Gall, 2016).

\section{3. ¿Quiénes son los estudiantes normalistas?}

Por tradición, las Escuelas Normales han formado a los docentes de Educación Básica, ofreciendo licenciaturas en Educación Preescolar, Primaria, Secundaria, Educación Física y Educación 
Especial. Una gran heterogeneidad caracteriza a estas instituciones, tanto en su personal docente como en el alumnado. De acuerdo con datos proporcionados por el INEE (2017), en el ciclo escolar 2015-2016 se inscribieron 108.555 estudiantes en alguna licenciatura de Educación Normal, atendidos por 15.602 docentes en 460 Escuelas Normales a nivel nacional. En las normales públicas se reporta una población de 5.197 alumnos, de los cuales $76.7 \%$ son mujeres y $23.3 \%$ son varones, lo que refuerza la idea que por tradición el magisterio ha sido una profesión principalmente femenina. Las edades de los jóvenes son: menores de 18 años, 1.3\%; de 18-23 años, 80.7\%; 24 años y más $18 \%$, lo que refleja una población mayoritariamente joven (SEP-SIBEN, 2016). Esta misma fuente señala que $2.2 \%$ de la población total son hablantes de lengua indígena, concentrados en las licenciaturas de Educación Preescolar Intercultural Bilingüe y Educación Primaria Intercultural Bilingüe en instituciones ubicadas en el sureste del país principalmente. Asimismo, los datos muestran que $89.1 \%$ de la población estudiantil egresa de las escuelas normales y $88.5 \%$ se titulan en corto tiempo.

Los estudiantes de las escuelas normales estarán en un futuro próximo en las aulas con la función social de educar a las nuevas generaciones de ciudadanos. Serán ellos los encargados de transmitir concepciones, ideas, actitudes, formas de ser y de pensar con respecto a los otros, en este caso, hacia los grupos étnicos. En estudios de organismos internacionales (UNESCO, 2017) y trabajos de autores especialistas del tema (Bolívar, 2007;
Conde, 2004; Florescano, et al., 2015; Levinson y Berumen, 2007; Schmelkes, 2013, 2009, 2004) se ha señalado reiteradamente el papel trascendente de la escuela en la educación ciudadana de niños y jóvenes. También se insiste en la importancia de que en los proyectos educativos a nivel nacional se incorpore de manera urgente asignaturas vinculadas con Educación Ciudadana en la formación inicial de los docentes (Bolívar, 2007; Elizondo, Stig y Ruiz, 2007; Peinado, 2013), revisando contenidos, métodos y estrategias didácticas que garanticen el papel de los maestros en la preparación de los nuevos ciudadanos. Esta investigación pretende promover la discusión sobre la necesidad de reforzar la Ciudadanía Cultural en la Escuelas Normales, a partir de indagar actitudes y comportamientos de los jóvenes con respecto a la diversidad cultural.

\section{Metodología}

\section{Universo y Muestra}

El universo de las 6 Escuelas Normales públicas de la CDMX está conformado por 5927 alumnos; para el estudio se eligieron 5 instituciones: 1 (ENE); 2 (ENMJN); 3 (BENM); 4 (ENSM); 5 (ESEF), lo que conforma una "población finita" (Sánchez, 2007) acotada a la matrícula del ciclo escolar 2015-2016. De esta población se seleccionó una muestra de 319 jóvenes, que corresponde a $5.38 \%$, la cual no es representativa del universo porque no se pretende generalizar los resultados (López, 1998) a toda la población de estudiantes de las escuelas normales; se trata de indagar algunas actitudes de la cultura ciudada- 
na; por tanto, los resultados son válidos únicamente para el grupo muestra.

Se utilizó un muestreo aleatorio simple (Festinger y Katz, 1972) en donde los participantes fueron integrándose al grupo de manera espontánea a invitación de la coordinadora o de alguno de sus profesores. De la muestra, 247 son mujeres que corresponden al $77.4 \%$ y 72 son hombres equivalente a $22.5 \%$ de la muestra; sus edades fluctúan de 17 a 47 años. Entre los alumnos encuestados, ninguno reconoció ser hablante de alguna lengua indígena, aunque $35 \%$ registró tener vínculos familiares -padres, abuelos, tíos, compadres- con algún grupo de ascendencia indígena.

\section{Instrumentos}

El trabajo empírico se centró en la aplicación de dos instrumentos: un cuestionario y una asociación de palabras. Por cuestiones de espacio, aquí se presenta únicamente el análisis e interpretación de la asociación de palabras, lo cual significa una limitación en términos del alcance e interpretación de los resultados. La asociación de palabras forma parte de los llamados métodos asociativos (Abric, 2001), los cuales fundamentan que a partir de un término inductor, el encuestado relaciona con palabras o imágenes situaciones $\mathrm{u}$ objetos que asocia con la pregunta; así, es posible acercarse a los elementos semánticos que surgen de manera inmediata en la mente de la persona. Para el análisis se aplicó la técnica de redes semánticas naturales, propuesta inicialmente por Figueroa, González y Solís (1981); Reyes (1993) y Valdés (1998) y reforzada con investigaciones más recientes por Murillo y Becerra (2009); Hinojosa (2008) y Vera, Bautista y Batista (2005), las cuales permiten, a partir de su rigurosa utilización, interpretar las palabras expresadas por los informantes para llegar a la estructura interna de los significados.

\section{Procedimiento}

Para el análisis se emplearon los principales indicadores de la técnica: tamaño de la red (TR); peso semántico (PS); y núcleo de la red (NR). Se solicitó a los estudiantes anotaran 3 palabras que asociaran con el término inductor indígena y las jerarquizaran. Las primeras palabras de la lista son las que contienen el mayor peso semántico (PS) y constituyen el núcleo de la red (NR). El total de palabras expresadas por los estudiantes sobre el vocablo indígena se trabajó de manera independiente por institución para ahondar en los significados de cada grupo de jóvenes.

Se utilizaron 3 categorías de análisis construidas en investigaciones anteriores (Piña, 2011) relacionadas con los grupos vulnerables: aceptación, entendida como aprobación y acepción de personas, considerar algo como positivo, bueno. Para el caso de los indígenas se refiere a la convivencia plena, sin importar características físicas o culturales; discriminación, que se define como separar, diferenciar una cosa de otra, dar trato de inferioridad a una persona o grupo por motivos culturales, sociales y/o físicos. En el caso que nos ocupa, significa rechazar y excluir de la convivencia y del grupo social a quienes son diferentes por razones étnicas; y denuncia, 
que consiste en declarar un estado o situación irregular o inconveniente de algo; en el caso de los grupos indígenas, significa manifestar públicamente las situaciones de injusticia, inequidad, miseria y abandono que durante siglos han caracterizado a estas comunidades. Reyes (1993), especialista en redes semánticas naturales, afirma: "es necesario trabajar con las estructuras generadas por los sujetos” (p. 86), es decir, partir de las palabras expresadas directamente por los estudiantes y plasmadas en una lista según el orden de importancia, como lo enfatiza la autora:

Con base en esta lista, y a los valores asignados a las definidoras (jerarquía), se logra tener un mapeo de la organización de la información en memoria [...] en forma de red, en donde las palabras o eventos forman relaciones, las cuales como conjunto dan el significado. El significado, consecuentemente, es el resultante de un proceso reconstructivo de información en la memoria el cual nos da el conocimiento de un concepto [...] entre mayor sea la red se podrá tener una mejor comprensión y conocimiento acerca de lo que para los sujetos significa la idea definidora (Reyes, 1993: 86).

En las tablas siguientes se expone la totalidad de vocablos expresados por los jóvenes de cada institución, con el PS y porcentaje del PS de cada término. Posteriormente se muestra el núcleo de la red, el cual concentra las palabras con mayor PS y mayor porcentaje, es decir, aquellas que por su valor semántico resultaron las más significativas y reveladoras de lo que piensa este grupo de jóvenes. En la red del total de palabras, los términos de aceptación tienen fondo blanco; los vocablos de discriminación se ubican con fondo morado y las palabras de denuncia, se señalaron con fondo azul.

\section{Resultados por institución}

Según se observa en la tabla 1, el PS del total de palabras suma 405; los términos se agruparon de mayor a menor con un porcentaje máximo de 6.4 , lo cual indica que pocos concentraron la significatividad de la palabra indígena. En la red total aparecen 16 términos de discriminación, que corresponden a $7.4 \%$, sin embargo, por su bajo PS y mínima representatividad no aparecen en el núcleo de la red. A continuación se presenta el núcleo de la red, de donde se seleccionaron las palabras con PS mayor a 5 y que se muestran en la tabla 2: 


\section{Institución 1 (ENE)}

Las palabras expresadas sumaron 405 de PS y se presenta la red a continuación:

Tabla 1. Total de palabras expresadas por los estudiantes

\begin{tabular}{|c|c|c|}
\hline Palabras & PS & \% PS \\
\hline Cultura & 26 & 6.4 \\
\hline Discriminación & 26 & 6.4 \\
\hline Respeto & 26 & 6.4 \\
\hline Pobreza & 22 & 5.4 \\
\hline Igualdad & 19 & 4.7 \\
\hline Humildad & 14 & 3.5 \\
\hline Lengua & 14 & 3.5 \\
\hline Trabajadores & 13 & 3.2 \\
\hline Apoyo & 11 & 2.7 \\
\hline Tradiciones & 10 & 2.5 \\
\hline Inteligentes & 9 & 2.2 \\
\hline Pueblos & 9 & 2.2 \\
\hline Oportunidades & 8 & 2.0 \\
\hline Exclusión & 6 & 1.5 \\
\hline & & \\
Humano & 6 & 1.5 \\
\hline Persona & 6 & 1.5 \\
\hline Convivencia & 4 & 1.0 \\
\hline Costumbres & 4 & 1.0 \\
\hline Marginados & 4 & 1.0 \\
\hline Mexicanos & 4 & 1.0 \\
\hline Raíces & 4 & 1.0 \\
\hline Sabiduría & 4 & 1.0 \\
\hline Sociedad & 4 & 1.0 \\
\hline & & \\
Admiración & 3 & 0.7 \\
\hline Ahui & 3 & 0.7 \\
\hline Artesanal & 3 & 0.7 \\
\hline Comunicación & 3 & 0.7 \\
\hline Comunidades & 3 & 0.7 \\
\hline Conocimiento & 3 & 0.7 \\
\hline Diferentes & 3 & 0.7 \\
\hline Divertido & 3 & 0.7 \\
\hline Educación & 3 & 0.7 \\
\hline Egoístas & 3 & 0.7 \\
\hline Ejemplares & 3 & 0.7 \\
\hline Ignorancia & 3 & 0.7 \\
\hline
\end{tabular}

\begin{tabular}{|c|c|c|}
\hline Palabras & PS & $\begin{array}{c}\text { PS } \\
\text { PS }\end{array}$ \\
\hline Inocentes & 3 & 0.7 \\
\hline Migración & 3 & 0.7 \\
\hline Moreno & 3 & 0.7 \\
\hline Nativos & 3 & 0.7 \\
\hline Origen & 3 & 0.7 \\
\hline Problemas & 3 & 0.7 \\
\hline Rechazo & 3 & 0.7 \\
\hline Resistencia & 3 & 0.7 \\
\hline Ser Humano & 3 & 0.7 \\
\hline Tolerancia & 3 & 0.7 \\
\hline Amistad & 2 & 0.5 \\
\hline Analfabeta & 2 & 0.5 \\
\hline Antigüedad & 2 & 0.5 \\
\hline Aprendizajes & 2 & 0.5 \\
\hline Bajos & & \\
recursos & 2 & 0.5 \\
\hline Calidad & 2 & 0.5 \\
\hline Campo & 2 & 0.5 \\
\hline Cansado & 2 & 0.5 \\
\hline Comprensión & 2 & 0.5 \\
\hline Desempleo & 2 & 0.5 \\
\hline Desigualdad & 2 & 0.5 \\
\hline Desprotegido & 2 & 0.5 \\
\hline Empeño & 2 & 0.5 \\
\hline & & \\
Enseñar & 2 & 0.5 \\
\hline Equidad & 2 & 0.5 \\
\hline Esperanza & 2 & 0.5 \\
\hline Guerreras & 2 & 0.5 \\
\hline Identidad & 2 & 0.5 \\
\hline Indio & 2 & 0.5 \\
\hline Inmersión & 2 & 0.5 \\
\hline Integración & 2 & 0.5 \\
\hline Interesante & 2 & 0.5 \\
\hline Leal & 2 & 0.5 \\
\hline Nuevos & 2 & 0.5 \\
\hline Nutrición & 2 & 0.5 \\
\hline
\end{tabular}

\begin{tabular}{|c|c|c|}
\hline Palabras & PS & $\begin{array}{l}\% \\
\text { PS }\end{array}$ \\
\hline Responsabilidad & 2 & 0.5 \\
\hline Semejantes & 2 & 0.5 \\
\hline Sobresalientes & 2 & 0.5 \\
\hline Tímidos & 2 & 0.5 \\
\hline Tristeza & 2 & 0.5 \\
\hline Abuso & 1 & 0.2 \\
\hline Amigables & 1 & 0.2 \\
\hline Carencias & 1 & 0.2 \\
\hline Dedicados & 1 & 0.2 \\
\hline Diego & 1 & 0.2 \\
\hline Entendimiento & 1 & 0.2 \\
\hline Explotación & 1 & 0.2 \\
\hline Falta de cultura & 1 & 0.2 \\
\hline Falta de recursos & 1 & 0.2 \\
\hline Honesto & 1 & 0.2 \\
\hline Inclusión & 1 & 0.2 \\
\hline Incultos & 1 & 0.2 \\
\hline Limitadas & 1 & 0.2 \\
\hline Luchonas & 1 & 0.2 \\
\hline Maíz & 1 & 0.2 \\
\hline Maltrato & 1 & 0.2 \\
\hline Mente & 1 & 0.2 \\
\hline Noble & 1 & 0.2 \\
\hline $\begin{array}{c}\text { Poco } \\
\text { entendimiento }\end{array}$ & 1 & 0.2 \\
\hline Prejuicio & 1 & 0.2 \\
\hline Rol & 1 & 0.2 \\
\hline Segregado & 1 & 0.2 \\
\hline Sucio & 1 & 0.2 \\
\hline Valientes & 1 & 0.2 \\
\hline Valores & 1 & 0.2 \\
\hline Vida & 1 & 0.2 \\
\hline Total & 405 & 100 \\
\hline
\end{tabular}

Fuente: elaboración propia 
Tabla 2. Institución 1. Núcleo de la Red

\begin{tabular}{|c|c|c|}
\hline Palabras & PS & \% PS \\
\hline Cultura & 26 & 11.6 \\
\hline Discriminación & 26 & 11.6 \\
\hline Respeto & 26 & 11.6 \\
\hline Pobreza & 22 & 9.8 \\
\hline Igualdad & 19 & 8.4 \\
\hline Humildad & 14 & 6.2 \\
\hline Lengua & 14 & 6.2 \\
\hline Trabajadores & 13 & 5.8 \\
\hline Apoyo & 11 & 4.9 \\
\hline Tradiciones & 10 & 4.4 \\
\hline Inteligentes & 9 & 4.0 \\
\hline Pueblos & 9 & 4.0 \\
\hline Oportunidades & 8 & 3.6 \\
\hline Exclusión & 6 & 2.7 \\
\hline Humano & 6 & 2.7 \\
\hline Persona & 6 & 2.7 \\
\hline Total & $\mathbf{2 2 5}$ & $\mathbf{1 0 0 . 0}$ \\
\hline
\end{tabular}

Fuente: elaboración propia

Como se observa en la tabla 2, en la institución 1, 16 palabras conforman el núcleo de la red, destacándose términos como cultura, discriminación y respeto, con 26 de PS cada una y $11.6 \%$ el PS más alto. Continúan términos como pobreza (22), igualdad (19), humildad (14) y lengua (14) que también obtienen alto PS. Se observa un porcentaje significativo de términos de Aceptación (81.2\%), lo que puede representar que las nociones de Cultura Ciudadana a nivel curricular o experiencial han impactado a estos jóvenes, quienes valoran el legado histórico y cultural que dichas comunidades han heredado a la sociedad mexicana. También se advierten tres vocablos de Denuncia (18.7\%) para señalar el estado de abandono social, económico y cul- tural del que han sido objeto estos grupos durante siglos por parte de los gobiernos e instancias responsables. Llama la atención la ausencia de términos discriminatorios en el núcleo de la red, situación muy diferente a la observada en otras instituciones de Educación Superior (Piña, 2011), en dónde dichas palabras no únicamente se hacen presentes, sino que además obtuvieron porcentajes muy altos.

En la tabla 3, el porcentaje máximo del PS es de $12.7 \%$. Muchas palabras alcanzaron únicamente décimas de porcentaje, lo cual indica su escasa significatividad. En la red total hay 14 términos de discriminación correspondientes a $10.5 \%$; sin embargo, por su mínima representatividad, 


\section{Institución 2 (ENMJN)}

Las palabras expresadas sumaron 395 de PS y se presenta la red a continuación:

Tabla 3. Institución 2. Total de palabras expresadas por los estudiantes

\begin{tabular}{|l|c|c|}
\hline \multicolumn{1}{|c|}{ Palabras } & PS & \% PS \\
\hline Cultura & 50 & 12.7 \\
\hline Discriminación & 47 & 11.9 \\
\hline Pobreza & 36 & 9.1 \\
\hline Trabajadores & 20 & 5.1 \\
\hline Respeto & 17 & 4.3 \\
\hline Artesanías & 13 & 3.3 \\
\hline Lengua & 12 & 3 \\
\hline Tradiciones & 12 & 3 \\
\hline Dialecto & 11 & 2.8 \\
\hline Humildad & 10 & 2.5 \\
\hline Pueblos & 10 & 2.5 \\
\hline Costumbres & 9 & 2.3 \\
\hline Valores & 8 & 2 \\
\hline Igualdad & 6 & 1.5 \\
\hline Racismo & 6 & 1.5 \\
\hline Vestimenta & 6 & 1.5 \\
\hline Amabilidad & 5 & 1.3 \\
\hline Capaces & 5 & 1.3 \\
\hline Experiencia & 5 & 1.3 \\
\hline Oportunidades & 5 & 1.3 \\
\hline Amigos & 4 & 1 \\
\hline Ignorancia & 4 & 1 \\
\hline Rural & 4 & 1 \\
\hline Aprender & 3 & 0.8 \\
\hline & & \\
\hline
\end{tabular}

\begin{tabular}{|l|c|c|}
\hline \multicolumn{1}{|c|}{ Palabras } & PS & \% PS \\
\hline $\begin{array}{l}\text { Comunicación } \\
\text { difícil }\end{array}$ & 3 & 0.8 \\
\hline Convivencia & 3 & 0.8 \\
\hline Creencias & 3 & 0.8 \\
\hline Desigualdad & 3 & 0.8 \\
\hline Empatía & 3 & 0.8 \\
\hline Genial & 3 & 0.8 \\
\hline Ingeniosos & 3 & 0.8 \\
\hline Inteligencia & 3 & 0.8 \\
\hline Miedo & 3 & 0.8 \\
\hline Persona & 3 & 0.8 \\
\hline $\begin{array}{l}\text { Riqueza } \\
\text { cultural }\end{array}$ & 3 & 0.8 \\
\hline Sabiduría & 3 & 0.8 \\
\hline Sobresalientes & 3 & 0.8 \\
\hline Violencia & 3 & 0.8 \\
\hline Auténtico & 2 & 0.5 \\
\hline Desfavorecidos & 2 & 0.5 \\
\hline Diversidad & 2 & 0.5 \\
\hline Encarcelados & 2 & 0.5 \\
\hline Estado & 2 & 0.5 \\
\hline Huarachitos & 2 & 0.5 \\
\hline Humanistas & 2 & 0.5 \\
\hline Maltrato & 2 & 0.5 \\
\hline Orgullo & 2 & 0.5 \\
\hline Orígenes & 2 & 0.5 \\
\hline
\end{tabular}

\begin{tabular}{|l|c|c|}
\hline \multicolumn{1}{|c|}{ Palabras } & PS & \% PS \\
\hline $\begin{array}{l}\text { Pocas } \\
\text { oportunidades }\end{array}$ & 2 & 0.5 \\
\hline Rezago & 2 & 0.5 \\
\hline $\begin{array}{l}\text { Saben lo que } \\
\text { quieren }\end{array}$ & 2 & 0.5 \\
\hline Analfabetismo & 1 & 0.3 \\
\hline Antisocial & 1 & 0.3 \\
\hline Burlas & 1 & 0.3 \\
\hline Colores & 1 & 0.3 \\
\hline Conocimientos & 1 & 0.3 \\
\hline Convivir & 1 & 0.3 \\
\hline Determinado & 1 & 0.3 \\
\hline Exclusión & 1 & 0.3 \\
\hline $\begin{array}{l}\text { Sin } \\
\text { conocimiento }\end{array}$ & 1 & 0.3 \\
\hline $\begin{array}{l}\text { Falta de } \\
\text { trabajo }\end{array}$ & 1 & 0.3 \\
\hline Historia & 1 & 0.3 \\
\hline Inseguros & 1 & 0.3 \\
\hline Intelectuales & 1 & 0.3 \\
\hline Interesante & 1 & 0.3 \\
\hline Intolerancia & 1 & 0.3 \\
\hline Marginales & 1 & 0.3 \\
\hline Sencillez & 1 & 0.3 \\
\hline $\begin{array}{l}\text { Sierra } \\
\text { tarahumara }\end{array}$ & 1 & 0.3 \\
\hline Trato & 1 & 0.3 \\
\hline & 395 & 100 \\
\hline Total & & \\
\hline
\end{tabular}

Fuente: elaboración propia 
no se incluyeron en el núcleo de la red, el cual se presenta en la siguiente tabla:

La diversidad de vocablos para significar a los indígenas en esta institución es amplia, según se observa en la tabla 4; hay 16 palabras con mayor significatividad como cultura (50), discriminación (47), pobreza (36) con alto PS, señal de la representatividad de dichos vocablos. De estas palabras con mayor PS, solo un término es de aceptación; los otros dos son vocablos de denuncia ante la situación social de los indígenas, lo cual puede ser un indicador de que los jóvenes de la muestra son conscientes de las situaciones desfavorables que viven estas comunidades. El vocablo cultura, que alcanza el mayor PS en tres de las cinco instituciones, muestra reconocimiento hacia la diversidad cultural y al conjunto de tradiciones heredadas por los grupos autóctonos; asimismo, la palabra pobreza, también presente en las cinco instituciones y con fuerte PS, muestra conciencia y comprensión sobre las condiciones de abandono social en que se hallan estos grupos. También obtienen alto PS términos como trabajadores (20), respeto (17) y artesanías (13), todos sinónimos de aceptación y reconocimiento. Se advierte la conformación del núcleo de la red: 13 palabras de aceptación (75\%) y tres términos de denuncia (18.8\%); estos últimos señalan la necesidad de manifestar las condiciones de vida de estos grupos sumidos en la miseria e injusticia social durante siglos.

Tabla 4. Institución 2. Núcleo de la Red

\begin{tabular}{|c|c|c|}
\hline Palabras & PS & \% PS \\
\hline Cultura & 50 & 18.3 \\
\hline Discriminación & 47 & 17.2 \\
\hline Pobreza & 36 & 13.2 \\
\hline Trabajadores & 20 & 7.3 \\
\hline Respeto & 17 & 6.2 \\
\hline Artesanías & 13 & 4.8 \\
\hline Lengua & 12 & 4.4 \\
\hline Tradiciones & 12 & 4.4 \\
\hline Dialecto & 11 & 4.0 \\
\hline Humildad & 10 & 3.7 \\
\hline Pueblos & 10 & 3.7 \\
\hline Costumbres & 9 & 3.3 \\
\hline Valores & 8 & 2.9 \\
\hline Igualdad & 6 & 2.2 \\
\hline Racismo & 6 & 2.2 \\
\hline Vestimenta & 6 & 2.2 \\
\hline Total & $\mathbf{2 7 3}$ & 100 \\
\hline
\end{tabular}

Fuente: elaboración propia 


\section{Institución 3 (BENM)}

Los jóvenes expresaron palabras con 354 de PS, según se observa en la red, a continuación en la tabla 5:

Tabla 5. Institución 3. Total de palabras expresadas por los estudiantes

\begin{tabular}{|l|c|c|}
\hline \multicolumn{1}{|c|}{ Palabras } & PS & \% PS \\
\hline Respeto & 48 & 13.6 \\
\hline Cultura & 37 & 10.5 \\
\hline Discriminación & 19 & 5.4 \\
\hline Humildad & 19 & 5.4 \\
\hline Igualdad & 18 & 5.1 \\
\hline Orgullo & 9 & 2.5 \\
\hline Pobreza & 9 & 2.5 \\
\hline Oportunidad & 8 & 2.3 \\
\hline Raíces & 8 & 2.3 \\
\hline Aprendizaje & 7 & 2 \\
\hline Lengua & 6 & 1.7 \\
\hline Superación & 6 & 1.7 \\
\hline Trabajadores & 6 & 1.7 \\
\hline Burlas & 5 & 1.4 \\
\hline Convivencia & 5 & 1.4 \\
\hline Humanos & 5 & 1.4 \\
\hline Interés & 5 & 1.4 \\
\hline Dialectos & 4 & 1.1 \\
\hline Equidad & 4 & 1.1 \\
\hline Inclusión & 4 & 1.1 \\
\hline Admiración & 3 & 0.8 \\
\hline Afectuosos & 3 & 0.8 \\
\hline Arte & 3 & 0.8 \\
\hline Conservador & 3 & 0.8 \\
\hline Derechos & 3 & 0.8 \\
\hline Diversidad & 3 & 0.8 \\
\hline Esfuerzo & 3 & 0.8 \\
\hline
\end{tabular}

\begin{tabular}{|l|c|c|}
\hline \multicolumn{1}{|c|}{ Palabras } & PS & $\begin{array}{c}\text { \% } \\
\text { PS }\end{array}$ \\
\hline Exclusión & 3 & 0.8 \\
\hline Justicia & 3 & 0.8 \\
\hline Lucha & 3 & 0.8 \\
\hline Marginación & 3 & 0.8 \\
\hline Música & 3 & 0.8 \\
\hline Necesidades & 3 & 0.8 \\
\hline Origen & 3 & 0.8 \\
\hline Padres & 3 & 0.8 \\
\hline Patrimonio \\
cultural & 3 & 0.8 \\
\hline Provinciano & 3 & 0.8 \\
\hline Sencillos & 3 & 0.8 \\
\hline Tradiciones & 3 & 0.8 \\
\hline Única & 3 & 0.8 \\
\hline Valentía & 3 & 0.8 \\
\hline Apreciar & 2 & 0.6 \\
\hline Comida & 2 & 0.6 \\
\hline Comunicación & 2 & 0.6 \\
\hline Conocer & 2 & 0.6 \\
\hline Costumbre & 2 & 0.6 \\
\hline Creatividad & 2 & 0.6 \\
\hline Dedicación & 2 & 0.6 \\
\hline Experiencia & 2 & 0.6 \\
\hline Explotación & 2 & 0.6 \\
\hline Fuerza & 2 & 0.6 \\
\hline Generoso & 2 & 0.6 \\
\hline Hospitalarios & 2 & 0.6 \\
\hline Integración & 2 & 0.6 \\
\hline
\end{tabular}

\begin{tabular}{|l|c|c|}
\hline \multicolumn{1}{|c|}{ Palabras } & PS & \%PS \\
\hline Náhuatl & 2 & 0.6 \\
\hline Paz & 2 & 0.6 \\
\hline Rechazo & 2 & 0.6 \\
\hline Rezago & 2 & 0.6 \\
\hline Sabiduría & 2 & 0.6 \\
\hline Solidaridad & 2 & 0.6 \\
\hline Valores & 2 & 0.6 \\
\hline Abuso & 1 & 0.3 \\
\hline Amabilidad & 1 & 0.3 \\
\hline Belleza & 1 & 0.3 \\
\hline Compartido & 1 & 0.3 \\
\hline Confiable & 1 & 0.3 \\
\hline Desigualdad & 1 & 0.3 \\
\hline $\begin{array}{l}\text { Falta de } \\
\text { trabajo }\end{array}$ & 1 & 0.3 \\
\hline Familia & 1 & 0.3 \\
\hline Identidad & 1 & 0.3 \\
\hline Importantes & 1 & 0.3 \\
\hline Inteligentes & 1 & 0.3 \\
\hline Legado & 1 & 0.3 \\
\hline Linaje & 1 & 0.3 \\
\hline Olvido & 1 & 0.3 \\
\hline Prejuicios & 1 & 0.3 \\
\hline Seguridad & 1 & 0.3 \\
\hline Sociedad & 1 & 0.3 \\
\hline Tolerancia & 1 & 0.3 \\
\hline Vulnerabilidad & 1 & 0.3 \\
\hline \multicolumn{1}{|c|}{ Total } & $\mathbf{3 5 4}$ & $\mathbf{1 0 0}$ \\
\hline
\end{tabular}

Fuente: elaboración propia 
El máximo PS fue 48, en donde destacan numerosos términos con bajo PS, lo cual refiere a su poca significatividad; sin embargo, se anotaron todos a fin de tener un panorama completo de la red. Llama la atención que sólo cuatro términos (3\%) son palabras de discriminación, pero no aparecen en el núcleo debido a su poca representatividad. Veamos en la tabla 6 el núcleo de la red de esta institución.

En la estructura del núcleo de la red (tabla 6), se observan 17 palabras con el máximo porcentaje de PS de 21.8, el cual es alto comparado con las otras escuelas normales. Destacan los términos con mayor PS: respeto (48) y cultura (37), asociados con la aceptación. Siguen vocablos como discriminación (19), que denota denuncia sobre la situación de vida de estos grupos; humildad (19), e igualdad (18), que también representan alta significatividad. Derivado de estos resultados, puede afirmarse que cinco términos contienen la mayor significatividad para este grupo de jóvenes. Se advierte que 14 de las expresiones son de aceptación (82.4\%) y tres (17.7\%) son palabras de denuncia: discriminación (19), pobreza (9), burlas (5).

En la red (tabla 7) se observa el total de palabras expresadas por los jóvenes de esta institución. La mayoría de los términos tienen PS bajo, lo cual representa una mínima significatividad por la diversidad de términos asociados con los

Tabla 6. Institución 3. Núcleo de la Red

\begin{tabular}{|l|c|c|}
\hline \multicolumn{1}{|c|}{ Palabras } & $\begin{array}{c}\text { Peso } \\
\text { Semántico }\end{array}$ & $\begin{array}{c}\text { \% } \\
\text { Peso Semántico }\end{array}$ \\
\hline Respeto & 48 & 21.8 \\
\hline Cultura & 37 & 16.8 \\
\hline Discriminación & 19 & 8.6 \\
\hline Humildad & 19 & 8.6 \\
\hline Igualdad & 18 & 8.1 \\
\hline Orgullo & 9 & 4.0 \\
\hline Pobreza & 9 & 4.0 \\
\hline Oportunidad & 8 & 3.6 \\
\hline Raíces & 8 & 3.6 \\
\hline Aprendizaje & 7 & 3.1 \\
\hline Lengua & 6 & 2.7 \\
\hline Superación & 6 & 2.7 \\
\hline Trabajadores & 6 & 2.7 \\
\hline Burlas & 5 & 2.2 \\
\hline Convivencia & 5 & 2.2 \\
\hline Humanos & 5 & 2.2 \\
\hline Interés & 5 & 2.2 \\
\hline \multicolumn{1}{|c|}{ Total } & $\mathbf{2 2 0}$ & $\mathbf{1 0 0}$ \\
\hline
\end{tabular}

Fuente: elaboración propia 


\section{Institución 4 (ENSM)}

Del total de palabras se obtuvo 322 de PS y 10.9\% de porcentaje máximo, el cual es bajo en relación a las otras instituciones. Únicamente siete palabras concentran la mayor carga semántica; el resto de los términos obtienen bajo PS, señalados a continuación en la tabla 7:

Tabla 7. Institución 4. Total de palabras expresadas por los estudiantes

\begin{tabular}{|l|c|c|}
\hline \multicolumn{1}{|c|}{ Palabra } & PS & $\begin{array}{c}\text { \% } \\
\text { PS }\end{array}$ \\
\hline Igualdad & 35 & 10.9 \\
\hline Respeto & 27 & 8.4 \\
\hline Trabajadores & 22 & 6.8 \\
\hline Cultura & 19 & 5.9 \\
\hline $\begin{array}{l}\text { Discriminaci } \\
\text { ón }\end{array}$ & 17 & 5.3 \\
\hline Lengua & 13 & 4 \\
\hline Tradiciones & 13 & 4 \\
\hline Personas & 9 & 2.8 \\
\hline Costumbres & 8 & 2.5 \\
\hline Humanos & 8 & 2.5 \\
\hline Humildad & 8 & 2.5 \\
\hline Convivencia & 7 & 2.2 \\
\hline Pobreza & 7 & 2.2 \\
\hline Sencillez & 7 & 2.2 \\
\hline Origen & 6 & 1.9 \\
\hline Amor & 5 & 1.6 \\
\hline Amable & 4 & 1.2 \\
\hline Competente & 4 & 1.2 \\
\hline Diversidad & 4 & 1.2 \\
\hline Sabiduría & 4 & 1.2 \\
\hline Superación & 4 & 1.2 \\
\hline Vestimenta & 4 & 1.2 \\
\hline
\end{tabular}

\begin{tabular}{|l|c|c|}
\hline \multicolumn{1}{|c|}{ Palabra } & PS & $\begin{array}{c}\text { \% } \\
\text { PS }\end{array}$ \\
\hline Agradables & 3 & 0.9 \\
\hline Analfabeta & 3 & 0.9 \\
\hline Apoyo & 3 & 0.9 \\
\hline Capaz & 3 & 0.9 \\
\hline Desigualdad & 3 & 0.9 \\
\hline Experiencia & 3 & 0.9 \\
\hline Honrados & 3 & 0.9 \\
\hline $\begin{array}{l}\text { Oportunidad } \\
\text { es }\end{array}$ & 3 & 0.9 \\
\hline Pocos & 3 & 0.9 \\
\hline Pueblo & 3 & 0.9 \\
\hline Relevantes & 3 & 0.9 \\
\hline $\begin{array}{l}\text { Sobresaliente } \\
\text { s }\end{array}$ & 3 & 0.9 \\
\hline Voluntad & 3 & 0.9 \\
\hline Aceptación & 2 & 0.6 \\
\hline Arte & 2 & 0.6 \\
\hline Castas & 2 & 0.6 \\
\hline $\begin{array}{l}\text { Conservador } \\
\text { es }\end{array}$ & 2 & 0.6 \\
\hline Derechos & 2 & 0.6 \\
\hline Ganas & 2 & 0.6 \\
\hline Honestos & 2 & 0.6 \\
\hline Identidad & 2 & 0.6 \\
\hline Ignorancia & 2 & 0.6 \\
\hline
\end{tabular}

\begin{tabular}{|l|c|c|}
\hline \multicolumn{1}{|c|}{ Palabra } & PS & $\begin{array}{c}\text { \% } \\
\text { PS }\end{array}$ \\
\hline Inteligencia & 2 & 0.6 \\
\hline Luchador & 2 & 0.6 \\
\hline Marginación & 2 & 0.6 \\
\hline Mexicanos & 2 & 0.6 \\
\hline Orgullo & 2 & 0.6 \\
\hline Recursos & 2 & 0.6 \\
\hline Sentimientos & 2 & 0.6 \\
\hline Sinceridad & 2 & 0.6 \\
\hline Valor & 2 & 0.6 \\
\hline Amistad & 1 & 0.3 \\
\hline Cariño & 1 & 0.3 \\
\hline Desnutrición & 1 & 0.3 \\
\hline Dialecto & 1 & 0.3 \\
\hline Emigrante & 1 & 0.3 \\
\hline Empatía & 1 & 0.3 \\
\hline Enseñantes & 1 & 0.3 \\
\hline Habla & 1 & 0.3 \\
\hline Importantes & 1 & 0.3 \\
\hline Injusticias & 1 & 0.3 \\
\hline $\begin{array}{l}\text { Reconocimien } \\
\text { to }\end{array}$ & 1 & 0.3 \\
\hline $\begin{array}{l}\text { Responsabilid } \\
\text { ad }\end{array}$ & 1 & 0.3 \\
\hline Total & 322 & 100 \\
\hline
\end{tabular}

Fuente: elaboración propia 
indígenas. Se ubicaron seis términos de discriminación (5.5\%); sin embargo, no aparecen en el núcleo debido a su mínima representatividad, mostrados a continuación en la tabla 8:

El núcleo de la red estuvo conformado por 16 palabras que obtuvieron el mayor PS, de las cuales 14 corresponden a aceptación (87.5\%) y únicamente dos $(\mathbf{1 2 . 5 \% )}$ pertenecen a la categoría denuncia. Pocos términos concentran la parte más densa de la red como igualdad (35), respeto (27), trabajadores (22), cultura (19), lengua (13)

Tabla 8. Institución 4. Núcleo de la Red y tradiciones (13), que son palabras asociadas con situaciones de aceptación hacia los grupos étnicos. También se advierten dos vocablos vinculados con situaciones de denuncia: discriminación (17) y pobreza (7), señalando cuestiones de injusticia social que continúan permeando la vida de los grupos originarios.

Se observan muchas palabras con bajo PS (tabla 9) y mínima representatividad: en esta institución hubo cinco términos de discriminación (7.2\%); sin embargo, debido a su baja representatividad, únicamente dos se incluyeron en el

\begin{tabular}{|c|c|c|}
\hline Palabra & PS & \% PS \\
\hline Igualdad & 35 & 16.6 \\
\hline Respeto & 27 & 12.8 \\
\hline Trabajadores & 22 & 10.4 \\
\hline Cultura & 19 & 9.0 \\
\hline Discriminación & 17 & 8.1 \\
\hline Lengua & 13 & 6.2 \\
\hline Tradiciones & 13 & 6.2 \\
\hline Personas & 9 & 4.3 \\
\hline Costumbres & 8 & 3.8 \\
\hline Humanos & 8 & 3.8 \\
\hline Humildad & 8 & 3.8 \\
\hline Convivencia & 7 & 3.3 \\
\hline Pobreza & 7 & 3.3 \\
\hline Sencillez & 7 & 3.3 \\
\hline Origen & 6 & 2.8 \\
\hline Amor & 5 & 2.4 \\
\hline Total & 211 & 100.0 \\
\hline
\end{tabular}

Fuente: elaboración propia 


\section{Institución 5 (ESEF)}

Del total de palabras se obtuvo 335 de PS y 11.9 de porcentaje, el cual es mínimo comparado con las otras escuelas; únicamente dos vocablos concentran el mayor PS. La tabla 9 muestra la red con todas las palabras expresadas por los jóvenes:

Tabla 9. Institución 5. Total de palabras expresadas por los estudiantes

\begin{tabular}{|l|c|c|}
\hline \multicolumn{1}{|c|}{ Palabra } & PS & \% PS \\
\hline Cultura & 40 & 11.9 \\
\hline Respeto & 35 & 10.4 \\
\hline Lengua & 19 & 5.7 \\
\hline Discriminación & 15 & 4.5 \\
\hline Humildad & 13 & 3.9 \\
\hline Igualdad & 11 & 3.3 \\
\hline Tradiciones & 9 & 2.7 \\
\hline Convivencia & 8 & 2.4 \\
\hline Dialecto & 8 & 2.4 \\
\hline Origen & 8 & 2.4 \\
\hline Pobreza & 6 & 1.8 \\
\hline Pueblo & 6 & 1.8 \\
\hline Trabajadores & 6 & 1.8 \\
\hline Admirable & 5 & 1.5 \\
\hline Amistad & 5 & 1.5 \\
\hline Comunicación & 5 & 1.5 \\
\hline Costumbres & 5 & 1.5 \\
\hline Persona & 5 & 1.5 \\
\hline Valores & 5 & 1.5 \\
\hline Amigo & 4 & 1.2 \\
\hline Diversidad & 4 & 1.2 \\
\hline Respeto & 4 & 1.2 \\
\hline Vestimenta & 4 & 1.2 \\
\hline Carencia & 3 & 0.9 \\
\hline Dadivoso & 3 & 0.9 \\
\hline & &
\end{tabular}

\begin{tabular}{|l|c|c|}
\hline \multicolumn{1}{|c|}{ Palabra } & PS & $\begin{array}{c}\text { \% } \\
\text { PS }\end{array}$ \\
\hline Diferencia & 3 & 0.9 \\
\hline Humano & 3 & 0.9 \\
\hline Limitación & 3 & 0.9 \\
\hline Marginación & 3 & 0.9 \\
\hline Nacionalidad & 3 & 0.9 \\
\hline Pobreza & 3 & 0.9 \\
\hline Reconocimiento & 3 & 0.9 \\
\hline Región & 3 & 0.9 \\
\hline Ser Humano & 3 & 0.9 \\
\hline Sujeto & 3 & 0.9 \\
\hline Aceptación & 2 & 0.6 \\
\hline Apoyo & 2 & 0.6 \\
\hline Aprendizaje & 2 & 0.6 \\
\hline Artistas & 2 & 0.6 \\
\hline Capaz & 2 & 0.6 \\
\hline Color & 2 & 0.6 \\
\hline Compromiso & 2 & 0.6 \\
\hline Confianza & 2 & 0.6 \\
\hline Conocimiento & 2 & 0.6 \\
\hline Costumbre & 2 & 0.6 \\
\hline Culturas & 2 & 0.6 \\
\hline Diálogo & 2 & 0.6 \\
\hline Exclusión & 2 & 0.6 \\
\hline Fortaleza & 2 & 0.6 \\
\hline & & \\
\hline & &
\end{tabular}

\begin{tabular}{|l|c|c|}
\hline \multicolumn{1}{|c|}{ Palabra } & PS & \% PS \\
\hline Hambre & 2 & 0.6 \\
\hline Humano & 2 & 0.6 \\
\hline Identidad & 2 & 0.6 \\
\hline Idioma & 2 & 0.6 \\
\hline Patrimonio & 2 & 0.6 \\
\hline Rechazo & 2 & 0.6 \\
\hline Recursos & 2 & 0.6 \\
\hline Responsable & 2 & 0.6 \\
\hline Artesanía & 1 & 0.3 \\
\hline Autoestima & 1 & 0.3 \\
\hline Autonomía & 1 & 0.3 \\
\hline Contexto & 1 & 0.3 \\
\hline Crecimiento & 1 & 0.3 \\
\hline Derechos & 1 & 0.3 \\
\hline Generosos & 1 & 0.3 \\
\hline Honesto & 1 & 0.3 \\
\hline Lengua & 1 & 0.3 \\
\hline Oportunidades & 1 & 0.3 \\
\hline Potencia & 1 & 0.3 \\
\hline Reprimido & 1 & 0.3 \\
\hline Rural & 1 & 0.3 \\
\hline Sociedad & 1 & 0.3 \\
\hline Tolerancia & 1 & 0.3 \\
\hline Total & 335 & 100 \\
\hline
\end{tabular}

Fuente: elaboración propia 
núcleo de la red, a continuación en la tabla 10:

Se muestra en el núcleo de la red (tabla 10) las 19 palabras más representativas de las expresadas por los jóvenes; se observan vocablos como cultura (40), respeto (35), lengua (19), humildad (13), igualdad (11) y tradiciones (9), todas representativas del reconocimiento y aceptación que muestran los jóvenes por las culturas originarias del país. También destacan en el núcleo términos como discriminación (15) y pobreza (6), que significan situaciones de denuncia social ante las condiciones de vida de los grupos étnicos. Sobresalen 15 palabras de aceptación (89.4\%), seguidas de dos términos de denuncia

Tabla 10. Institución 5. Núcleo de la Red
(9.8\%) y dos vocablos de discriminación (7.4\%). Cabe señalar que ésta fue la única institución en la que aparecen términos de discriminación en el núcleo de la red, que aún con bajo PS y mínima representatividad fueron expresadas por los estudiantes.

En la gráfica 1 se muestran los porcentajes totales obtenidos por cada una de las instituciones en los rubros de aceptación y denuncia:

$\mathrm{Al}$ analizar el conjunto de palabras expresadas por los estudiantes de las distintas escuelas normales y los porcentajes de aceptación y denuncia, puede confirmarse la presencia de cultura ciudadana, debido a que en el núcleo de la red

\begin{tabular}{|c|c|c|}
\hline Palabra & PS & \% PS \\
\hline Cultura & 40 & 18.7 \\
\hline Respeto & 35 & 16.4 \\
\hline Lengua & 19 & 8.9 \\
\hline Discriminación & 15 & 7.0 \\
\hline Humildad & 13 & 6.1 \\
\hline Igualdad & 11 & 5.1 \\
\hline Tradiciones & 9 & 4.2 \\
\hline Convivencia & 8 & 3.7 \\
\hline Dialecto & 8 & 3.7 \\
\hline Origen & 8 & 3.7 \\
\hline Pobreza & 6 & 2.8 \\
\hline Pueblo & 6 & 2.8 \\
\hline Trabajadores & 6 & 2.8 \\
\hline Admirable & 5 & 2.3 \\
\hline Amistad & 5 & 2.3 \\
\hline Comunicación & 5 & 2.3 \\
\hline Costumbres & 5 & 2.3 \\
\hline Persona & 5 & 2.3 \\
\hline Valores & 5 & 2.3 \\
\hline Total & $\mathbf{2 1 4}$ & $\mathbf{1 0 0 . 0}$ \\
\hline
\end{tabular}

Fuente: elaboración propia 
Gráfica 1. Porcentajes de Aceptación y Denuncia por institución

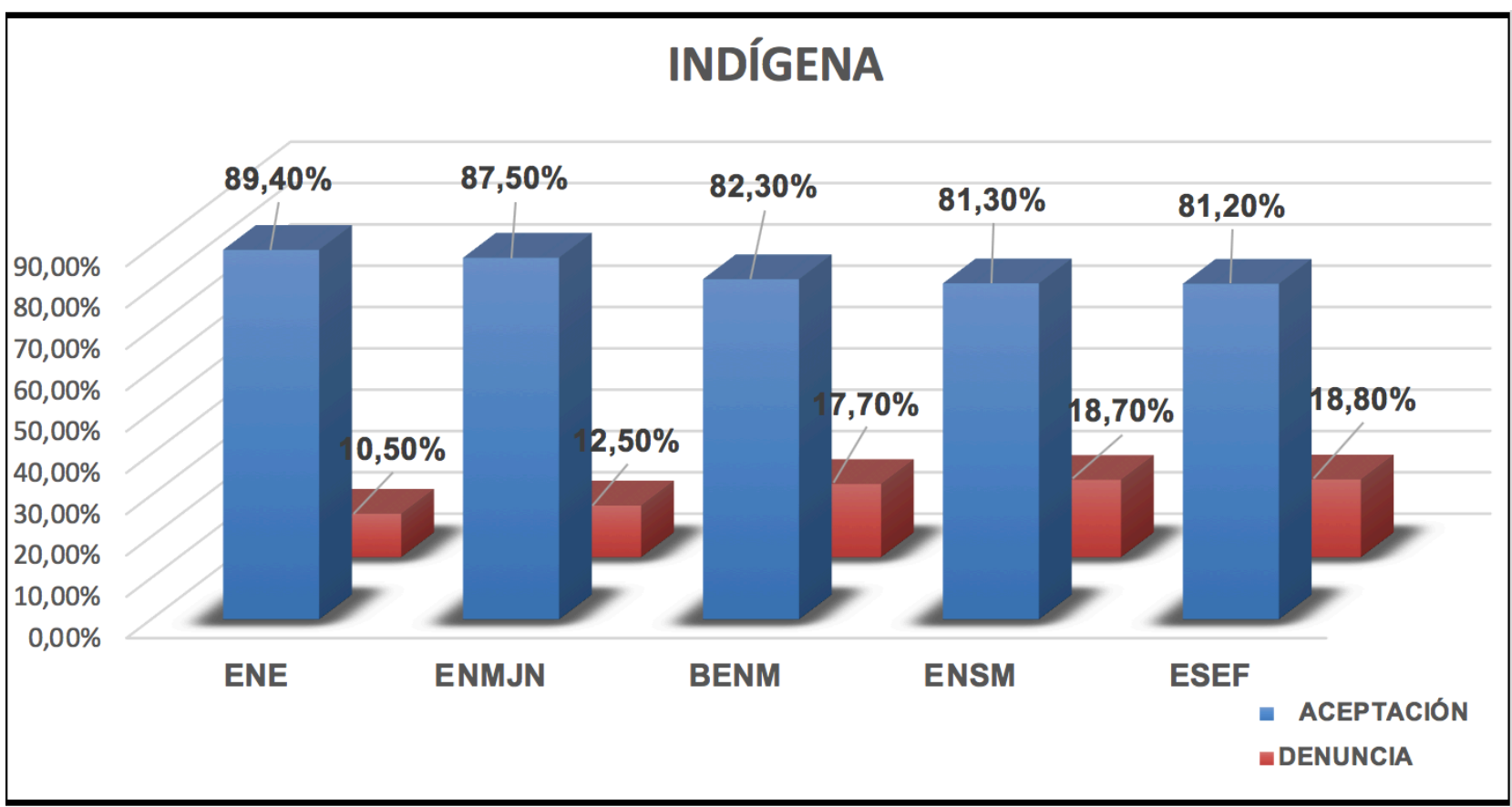

Fuente: elaboración propia

de las diferentes instituciones no hubo términos estigmatizantes ni de exclusión o discriminación; sin embargo, es necesario recordar que a diferencia de otros profesionistas, los estudiantes normalistas tienen la alta responsabilidad de educar a las nuevas generaciones de ciudadanos, razón por la cual es preocupante que los índices de aceptación apenas rebasen el $80 \%$, cuando la responsabilidad social que tendrán en el futuro exige de los docentes actitudes ciudadanas de mayor compromiso con la sociedad.

\section{Discusión de resultados}

Las sociedades actuales, caracterizadas por su diversidad étnica, lingüística y cultural, se construyen sobre la defensa de los derechos humanos universales (Levinson y Berumen, 2007) y el reconocimiento de los derechos culturales, también conocidos como "derechos diferenciados" (Kymlicka, 1996: 170) al interior de una cultura dominante, promoviendo el diálogo para alcanzar relaciones más igualitarias y equitativas. La revisión bibliográfica de trabajos a nivel internacional (Wade, 2011; Wieviorka, 2009; Espelt y Javaloy, s/f) muestra que fenómenos como el estigma, la exclusión, el racismo y las prácticas de discriminación no solamente no han desaparecido, sino que actualmente se presentan adoptando nuevas formas, veladas y sutiles. 
En México, la situación tampoco parece mejorar para los grupos minoritarios, generalmente en situación de vulnerabilidad, en donde especialistas del tema (Gall, 2016 y 2014; Paris, 2008; Velasco, 2015) continúan documentando situaciones de desigualdad, injusticia y discriminación velada o no hacia estos grupos. Frente a esta problemática, que no solamente no desaparece, sino que asume nuevas formas, la ciudadanía cultural emerge como posibilidad de acción y respuesta. Profundizar en las expresiones de estudiantes de Escuelas Normales públicas de la Ciudad de México permite reflexionar sobre la Educación Ciudadana de estos jóvenes y las posibilidades de incidir en esta dimensión durante su trayecto formativo. Los resultados muestran que muchos términos relacionados con el vocablo indígena contienen sentido positivo, como cultura, respeto, lengua y tradiciones, los cuales alcanzaron el mayor peso semántico; asimismo, palabras que denuncian la situación de desigualdad estructural que viven los indígenas también se colocaron con alto peso semántico, como discriminación y pobreza. Habrá que indagar a través de futuras investigaciones, cómo las instituciones formadoras de docentes están cumpliendo con su papel ineludible de educar para la ciudadanía y cómo estos futuros docentes, a su vez, contribuirán en la educación de los nuevos ciudadanos.

Organismos internacionales (UNESCO, 2017) y especialistas del campo (Schmelkes, 2013 y 2009; Stavenhagen, 2014) han señalado de manera reiterada el papel de la escuela y de los maestros en la adopción de actitudes y prácticas ciudadanas de los estudiantes; por tanto, ahondar en este terreno es necesario e impostergable para garantizar la formación de ciudadanos que abonen en la construcción de una sociedad más justa y democrática.

En los porcentajes de aceptación se observa que apenas rebasa $80 \%$, mientras la denuncia escasamente alcanza $20 \%$, lo cual podría indicar que todavía falta mucho por hacer en la consolidación de actitudes de reconocimiento frente a la diversidad cultural, característica principal del mosaico que conforma a la sociedad mexicana (Stavenhagen, 2014; Bonfil, 1989). Señalar que la intolerancia cultural está profundamente vinculada con la injusticia social y anclada en prejuicios y estereotipos colectivos (Cisneros, 2004), necesariamente lleva a la reflexión de los resultados sobre las actitudes y comportamientos de estos estudiantes, quienes tendrán la función de educar y contrarrestar fenómenos como el trato diferenciado, la exclusión social y la discriminación de las minorías en las poblaciones de niños y jóvenes que lleguen a las instituciones educativas.

\section{Conclusiones}

Por tradición las Escuelas Normales han sido las instituciones formadoras de docentes en México. Al cambiar el contexto internacional e impactar tales transformaciones en el ámbito nacional, estas entidades tienen la responsabilidad de adaptarse a los nuevos escenarios, donde la 
Ciudadanía Cultural ocupe un lugar principal. En los hallazgos de la investigación se observan altos índices de aceptación hacia los indígenas a través de vocablos que recuperan el legado cultural de estos grupos, así como de denunciar situaciones de injusticia y desigualdad que han caracterizado por siglos a estas comunidades. Los datos señalan la presencia de una cultura ciudadana en los jóvenes normalistas, probablemente no en su totalidad, pero sí se aprecian rasgos de aceptación y reconocimiento hacia estos grupos. Autores como Moreno (2016) hacen énfasis en la necesidad de distinguir el racismo "como un sistema totalizante y estructural" de la discriminación "como acto específico de diferenciación relacionado con alguna forma de injusticia" (p. 101). La discriminación se materializa en prácticas diferenciadoras y es a través de la denuncia cómo es posible "visibilizar las condiciones de abuso y opresión de estos grupos [...] la puesta en evidencia de la exclusión que viven los pueblos indígenas" (Moreno, 2016: 102).

Entre las posibles líneas de acción derivadas de este trabajo, se pretende fortalecer la línea de investigación Educación y Ciudadanía ya iniciada en el subsistema y de la cual este trabajo es producto; sin embargo, esta temática ha sido poco trabajada por los investigadores del gremio. Asimismo, se proyecta indagar a través de futuras investigaciones el estado de la cuestión en la planta académica, incluyendo las Escuelas Normales Bilingües ubicadas en el sureste del país, para conocer qué sucede con la aceptación de la diversidad cultural en estas latitudes.
Uno de los aportes principales del estudio hacia la comunidad científica es enfatizar la importancia de la Educación Ciudadana en los futuros docentes, quienes tendrán en sus manos la responsabilidad de educar a las nuevas generaciones de ciudadanos. También subrayar que técnicas como la asociación de palabras y las redes semánticas se han utilizado poco en la investigación educativa, constituyendo un excelente recurso para indagar significados. Asimismo, es necesario advertir que uno de los temas pendientes del presente estudio es analizar los contenidos de la asignatura Educación Ciudadana en los modelos curriculares de las instituciones formadoras de docentes, a fin de conocer las carencias formativas en este rubro y vislumbrar futuras investigaciones en el campo de la ciudadanía cultural en la formación de docentes.

\section{Referencias citadas:}

Abric, J.C. (2001): Prácticas sociales y representaciones, México, Coyoacán.

Aragón, A. (2015): Ciudadanía. La lucha por la inclusión y los derechos, México, UACM-Gedisa.

Benhabib, S. (2006): Las reivindicaciones de la cultura. Igualdad y diversidad en la era global, Buenos Aires, Katz.

Beuchot, M. (2005): Interculturalidad y Derechos Humanos. México, Siglo XXI-UNAM.

Bolívar, A. (2007): Escuela y formación para la ciuda- 
danía. Disponibleenweb:http://www.56714a0908ae2blf87aee2bf.pdf. [Consulta: 16 mayo 2017]

Bonfil, G. (1989): México Profundo. Una civilización negada, México, Grijalbo.

Borasteros, D. y J. García (2007): Un racismo de baja intensidad. El País, Sociedad, 3 noviembre, p. 32.

Casaús, M. (2009): "El Genocidio: la máxima expresión del racismo en Guatemala: una interpretación histórica y una reflexión", Nuevo Mundo Mundos Nuevos, Colloques, Jorneé d'Étude.

Castellanos, A. (2010): Racismo en México ¿Identidad y cultura? RAE. Racismo de ayer y hoy. Bolivia en el contexto mundial, Museo Nacional de Etnografía y Folklore, II, pp. 745-759.

Castellanos, A. (2012): La construcción del Otro en ciudades mexicanas. Del pensamiento liberal y la exclusión neoliberal, en A. Castellanos y G. Landázuri, Coords., Racismo y otras formas de intolerancia de Norte a Sur en América Latina, México, UAM-Iztapalapa, Juan Pablos Editor, pp. 99-124.

Cea, M. (2009): “La compleja detección del racismo y la xenofobia a través de una encuesta. Un paso adelante en su medición", Revista Española de Investigaciones Sociológicas, 125, pp. 13-45.

Cisneros, I. (2004): Formas modernas de la intolerancia. De la discriminación al genocidio, México, Océano.
Conde, S. (2004): Educar para la democracia. La educación ciudadana basada en el desarrollo de competencias cívicas y éticas, México, IFE.

Durán, V. (2004): Ciudadanía y Cultura Política. México, 1993-2001, México, Siglo XXI.

Elizondo, A., A. Stig y D. Ruiz (2007): “Democracia y ética en la escuela secundaria", Revista Mexicana de Investigación Educativa, 12(32), pp. 243-260.

Espelt, E.y F. Javaloy (s/f): El racismo moderno. Disponible en web:

https://www.ciudadredonda.org/admin/upload/ IMG/pdf/El_racismo_moderno.pdf [Consulta: 13 septiembre 2018]

Ferrajoli, L. (2008): “Universalismo de los derechos fundamentales y multiculturalismo", Boletín Mexicano de Derecho Comparado, 41(122), pp. 1135-1145

Festinger, L. y D. Katz (1972): Los métodos de investigación en las ciencias sociales, Barcelona, Paidós.

Figueroa, J., E. González y V. Solís (1981): “Una aproximación al problema del significado: las redes semánticas", Revista Latinoamericana de Psicología, 13(3), pp. 447-458.

Florescano, E., S. Conde, J. Gutiérrez y M. Chávez (2015): Cartilla Ciudadana, México, Fondo de Cultura Económica, Fundación Pueblo Hacia Arriba.

Gall, O. (2014): “Interseccionalidad e interdisciplina para entender y combatir el racismo", Interdiscipli- 
na, 4(2), pp. 9-34.

Gall, O. (2016): "Hilando fino entre las identidades, el racismo y la xenofobia en México y Brasil”, Desacatos, 51, pp. 8-17.

García-Canclini, N. (1995): Consumidores y ciudadanos: conflictos multiculturales de la globalización, México, Grijalbo.

Giménez, G. (2007): “Formas de discriminación en el marco de la lucha por el reconocimiento social", en Gall, O., Racismo, mestizaje y modernidad: visiones desde latitudes diversas, México, UNAM/Centro de Investigaciones Interdisciplinarias en Ciencias y $\mathrm{Hu}-$ manidades, pp. 37-61.

Gutiérrez, R. (2005): Cultura Política y Discriminación, México, CONAPRED.

Hamel, R. (2001): “Políticas del lenguaje y educación indígena en México. Orientaciones culturales y estrategias pedagógicas en una época de globalización”, en Bein, R. y Born, J., eds., Políticas lingüísticas. Norma e identidad, Buenos Aires, Universidad de Buenos Aires-Instituto de Lingüística, pp. 143-170.

Hernández, D. y R. Estrada (2012): “Antropología del ausentismo escolar entre niños indígenas de la Merced”, en Tuñón, E. y Rojas, M., coords., Género y migración II, San Cristóbal de las Casas, Chiapas, ECOSUR/El Colegio de la Frontera Norte/El Colegio de Michoacán/CIESAS, pp. 513-534.

Hinojosa, G. (2008): “El tratamiento estadístico de las redes semánticas naturales", Revista Internacional de Ciencias Sociales y Humanidades, 18(1), pp. 133-154.

INEE (2017): Panorama Educativo de México. Indicadores del Sistema Educativo Nacional 2016. Educación Básica y Media Superior, México, Instituto Nacional para la Evaluación de la Educación.

Knauth, L. (2000): "Los procesos del racismo", Desacatos, (4), pp. 13-26.

Kymlicka, W. (1996): Ciudadanía Multicultural, Barcelona, Paidós.

Kymlicka, W y W. Norman (1997): El retorno del ciudadano. Una revisión de la producción reciente en teoría de la ciudadanía. Disponible en web: https:// www.insumisos.com/lecturasinsumisas/Debate\%20 sobre\%20teoria\%20de\%20la\%20ciudadania.pdf [Consulta: 17 octubre 2017]

Levinson, B. y J. Berumen (2007): “Educación para una ciudadanía democrática en los países de América Latina: una mirada crítica”, REICE-Revista Electrónica Iberoamericana sobre calidad, eficiencia y cambio en educación, 5(4).

López, H. (1998): "La metodología de la encuesta", en Galindo, J., Coord., Técnicas de Investigación en sociedad, cultura y comunicación, México, Pearson Educación, pp. 33-73.

Marshall, T. H. (1967): “Ciudadanía y Clase Social”, Reis, 79(97), pp. 297-344. 
Moreno, M. (2016): "El archivo del estudio del racismo en México", Desacatos, 51, pp. 92-107.

Murillo, P. y S. Becerra (2009): “Las percepciones del clima escolar por directivos, docentes y alumnado mediante el empleo de <redes semánticas naturales $>$. Su importancia en la gestión de los centros educativos", Revista Educación, 350, pp. 375-399.

Ojeda, D. y M. González (2012): “Estereotipos de estudiantes universitarios hacia compañeros afrocolombianos e indígenas”, Revista CES Psicología, 5(2), pp. 101-118.

Paris, M. (2008): “Estratificación laboral, migración trasnacional y etnicidad", en Velasco, L. (Coord.), Migración, fronteras e identidades étnicas transnacionales. Versión digital (2015). Disponible en web: https://books.google.com.mx/books?hl=es\&lr=\&ci$\mathrm{d}=1 \mathrm{XA} 3 \mathrm{CwAAQBAJ} \& \mathrm{coi}=$ fnd $\& \mathrm{pg}=\mathrm{PT} 3 \& \mathrm{cdq}=$ migra cion, +fronteras+e+identidades+etnicas+tra.pdf [Consulta: 2 mayo 2016)

Pávez, I. (2012): “Inmigración y racismo: experiencias de la niñez peruana en Santiago de Chile. Si Somos Americanos", Revista de Estudios Transfronterizos, 12(1), pp. 75-99.

Peinado, M. (2013): “Educación para la ciudadanía. Una reflexión desde lo efímero (2007-2013)”, Íber Didáctica de las Ciencias Sociales, Geografía e Historia, 75, pp. 25-32.

Piña, J. (2011): Aceptación, estigma y discriminación. Estudiantes normalistas ante sectores vulnera- bles, México, Díaz de Santos.

Placencia, M. (2008): “'Hola María’: racismo y discriminación en la interacción interétnica cotidiana en Quito”, Discurso y Sociedad, 2(3), pp. 573-608.

Rahier, J. (2013): Mami, ¿qué será lo que quiere el negro?: representaciones racistas en la revista Vistazo, 1957-1991. Disponible en web: http://www.flacso. org.ec/docs/sfracrahier.pdf [Consulta: 17 noviembre 2016)

Ramírez, J. (2005): “Derechos de los ciudadanos en las decisiones globales”, en Esquivel y Covarrubias, Coord., La sociedad civil en la encrucijada. Los retos de la ciudadanía en un contexto global, México, Porrúa, pp. 69-98.

Reyes, I. (1993): “Las redes semánticas naturales, su conceptualización y su utilización en la construcción de instrumentos", Revista de Psicología Social y Personalidad, 9(1), pp. 81-97.

Rodríguez, J. (2006): Un marco teórico para la discriminación, México, CONAPRED, Colección Estudios No. 2.

Saldaña, A. (2013): “Racismo, proximidad y mestizaje: el caso de las mujeres en el servicio doméstico en México", Trayectorias, 15(37), pp. 73-89.

Sánchez, J. (2007): Estadística básica aplicada a la educación, Madrid, Editorial CCS.

Schmelkes, S. (2004): La formación de valores en la 
educación básica, México, SEP, Biblioteca para la Actualización del Maestro.

Schmelkes, S. (2009): “Interculturalidad, democracia y formación valoral en México", Revista Electrónica de Investigación Educativa, 11(2), pp. 1-10.

Schmelkes, S. (2013): “Educación para un México intercultural", Sinéctica, 40, pp. 1-12. Disponible en web: http://www.n40a2.pdf [Consulta: 25 abril 2016]

SEGOB (2014): Ley Federal para Prevenir y Eliminar la Discriminación, México, Secretaría de Gobernación.

SEP-SIBEN (2016): Matrícula para la licenciatura en las Escuelas Normales. Disponible en web: http:// www.estadisticas_2015-2016.xlsx [Consulta: 12 diciembre 2018]

Stavenhagen, R. (2014): Racismo e identidades en el mundo actual. Disponible en web: http://revistas.unam.mx/index.php/inter/article/viewFile/47771/42955 [Consulta: 8 mayo 2017]

Taylor, Ch. (2009): El muticulturalismo y la política del reconocimiento, México, Fondo de Cultura Económica.

Touraine, A. (1997): ¿Podremos vivir juntos?, México, Fondo de Cultura Económica.

Touraine, A. (2005): Un nuevo paradigma. Para comprender el mundo de hoy, Barcelona, Paidós, Estado y Sociedad, 135.
Traverso-Yépez, M. (2005): “Discursos racistas: institucionalización del racismo a través de las prácticas lingüísticas”, Revista Interamericana de Psicología, 39, pp. 61-70.

UNESCO (2017): La Formación Inicial Docente en Educación para la Ciudadanía en América Latina. Análisis comparado de seis casos nacionales. OREAL-UNESCO, Santiago. Disponible en web: http://www.unesco.org/new/fileadmin/MULTIMEDIA/FIELD/Santiago/pdf/Formacion-Inicial-Docente-en-Educacion-para-la-Ciudadani.pdf. [Consulta: 25 abril 2018]

Valdés, J. (1998): Las redes semánticas naturales: usos y aplicaciones en psicología social, México, Universidad Autónoma del Estado de México.

Velasco, L., Coord. (2015): Migración, fronteras e identidades étnicas trasnacionales. Versión digital. Disponible en web: https://books.google.com. $\mathrm{mx} /$ books? $\mathrm{hl}=\mathrm{es} \& \mathrm{lr}=\& \mathrm{cid}=1 \mathrm{XA} 3 \mathrm{CwAAQBAJ} \& \mathrm{coi}=\mathrm{fn}$ $\mathrm{d} \& \mathrm{pg}=\mathrm{PT} 3 \& \mathrm{dq}=$ migracion,+ fronteras $+\mathrm{e}+$ identida des+etnicas+tra [Consulta: 28 septiembre 2018]

Vera, J., C. Bautista y F. Batista (2005): “Redes semánticas naturales. Aspectos teóricos, técnicos, metodológicos y analíticos”, Revista Ra Ximhai, 1(3), pp. 439-451.

Wade, P. (2011): "Multiculturalismo y racismo", Revista Colombiana de Antropología, 47 (2), pp.15-35.

Wade, P. (2014): Raza, ciencia y sociedad. Disponible en web: http://www.47204-127456-1-PB.pdf [Con- 
sulta: 13 mayo 2016]

Wieviorka, M. (2007): “La mutación del racismo”, Revista Mexicana de Ciencias Políticas y Sociales, 49(200), pp.13-23.

Wieviorka, M. (2009): El racismo. Una introducción, Barcelona, Gedisa.

\section{Notas:}

1Existe un debate teórico en torno a la discusión si la universalidad e igualdad de los derechos humanos fundamentales se opone a los derechos de los grupos (derechos colectivos) a mantener sus diferencias culturales. Desde una visión preservacionista, solo el reconocimiento explícito de la identidad y las diferencias culturales garantizan el respeto por las diferencias étnicas, sociales, sexuales, religiosas, políticas, culturales y su plena integración al Estado. Otra perspectiva sostiene que el concepto ciudadanía moderna ya integra las diferencias culturales y es la posibilidad más viable de ejercer los derechos humanos y la autonomía respetando las identidades culturales. Esta postura defiende que los derechos individuales no se contraponen con los colectivos, pero que los colectivos no son titulares de derechos. Se enfatiza en que los derechos individuales siempre son de personas, de individuos, no de colectivos y en ocasiones, es necesario incluso, proteger a las personas de algunas prácticas culturales lesivas -infibulación, extirpación de clítoris, venta de personas, vejaciones, humillaciones- que lesionan la dignidad y los derechos humanos. 